\title{
Facility layout for cellular manufacturing system under dynamic conditions
}

\author{
Amir-Mohammad Golmohammadi ${ }^{a *}$, Hamid Bani-Asadi ${ }^{\mathrm{b}}$, Hamid Esmaeelic ${ }^{\mathrm{c}}$ Hengameh Hadian ${ }^{\mathrm{d}}$ and $^{\mathrm{s}}$ \\ Farzaneh Bagheri ${ }^{\mathrm{e}}$
}

${ }^{a}$ Ph.D. Student of Industrial Engineering, University of Yazd, Yazd, Iran

${ }^{b}$ Graduate student of Industrial Engineering, Department of Industrial Engineering, Naragh Branch, Islamic Azad University, Iran

${ }^{c}$ Assistant Professor, Department of Industrial Engineering, North Tehran Branch, Islamic Azad University, Tehran, Iran

${ }^{d}$ Faculty Member of Nahavand University, Department of Industrial Engineering, Nahavand, Iran

${ }^{e}$ Graduate Student of Industrial Engineering, University of Yazd, Yazd, Iran

\section{H R O N I C L E}

Article history:

Received October 25, 2015

Received in revised format:

December 12, 2015

Accepted February 4, 2016

Available online

Februray 62016

Keywords:

Cellular manufacturing

Dynamic conditions

Facility layout

Cell formation

Hierarchical Genetic Algorithm

\section{A B S T R A C T}

Cellular manufacturing is considered as a lean technique of producing similar parts using sells or groups of team members, workstations, or equipment to facilitate operations by removing setup and unnecessary cost components among various operations. Cell formation and layout planning are the most components of the cellular manufacturing. This paper presents a dynamic method to minimize different costs including the total cost of movements within and between cells and exceptional parts. In this study, the Hierarchical Genetic Algorithm (HGA) is used for solving the resulted model and the results are compared with genetic algorithm. The results have indicated that the proposed method could reach optimal solutions for some small and medium sized problems in reasonable amount of time.

(C) 2016 Growing Science Ltd. All rights reserved.

\section{Introduction}

Cellular manufacturing is considered as a lean technique of producing similar parts using sells or groups of team members, workstations, or equipment to facilitate operations by removing setup and unnecessary cost components among various operations (Ming \& Ponnambalam, 2008). Cell formation and layout planning are the most components of the cellular manufacturing (Dixit \& Mishra, 2009). Co and Araar (1988) presented a three-stage procedure for configuring machines into manufacturing cells, and assigning the cells to process specific sets of jobs and offered a direct-search method for defining the composition of manufacturing ceils. Vakharia and Wemmerlov (1990) offered a cell formation technique, which combines the problems of cell formation and within-cell material flows. Houshyar and McGINNIS (1990) implemented a cut method to the corresponding quadratic assignment

* Corresponding author.

E-mail address: amir.m.golmohammadi@stu.yazd.ac.ir (A.-M. Golmohammadi)

(C) 2016 Growing Science Ltd. All rights reserved.

doi: $10.5267 /$ j.dsl.2016.2.001 
problem, and proposed a heuristic which produces a good solution. Logendran (1991) investigated the effect of sequence of operations and layout of cells in cellular manufacturing. They offered a technique, which includes two important factors and presented for determining optimal/near-optimal machine-part clusters in cellular manufacturing. Alfa et al. (1992) presented the simultaneous solution of the machine grouping and layout problems in cellular manufacturing systems. Balasubramanian and Panneerselvam (1993) investigated a method, which facilitates the formation, of machine groups. For a given set of components and their process routeing, the method first looked for several possible cells and then proposed a similarity matrix to reflect the components' routeing similarity with that of the arrangement of the facilities in the cell. They also proposed a heuristic procedure for tackeling the 'covering problem' to detect an economical number of manufacturing cells and cell arrangements such that each cell is determined to process specific component(s).

Chandrasekharan and Rajagopalan (1993) propsoed a multidimensional scaling algorithm for group layout in cellular manufacturing. Tavakkoli-Moghaddam et al. (2007) presented a model to solve a facility layout problem in cellular manufacturing systems (CMSs) with stochastic demands. Chan et al. (2008) proposed a two-phase approach to tackle the cell formation problem (CFP) by taking into account both intra-cell and inter-cell part movements. Mahdavi and Mahadevan (2008) proposed an algorithm for cellular manufacturing system and layout design based on sequence data. Paydar et al. (2008) proposed a fuzzy goal programming based method to handle an extended multi-objective mathematical linear programming model to tackle two essential problems in cellular manufacturing systems simultaneously: Cell formation and layout design.

Ahi et al. (2009) presented a method to determine cell formation, intracellular machine layout and cell layout in the CMS problem based on Technique for Order of Preference by Similarity to Ideal Solution (TOPSIS) (Hwang \& Yoon, 1981) method. Chang et al. (2009) presented a method for cell formation and cell layout design in cellular manufacturing system. Mahdavi et al. (2010) proposed a mathematical model for the joint problem of the cell formation problem and the machine layout where the objective was to minimize the total cost of inter-cell and intra-cell movements and the investment cost of machines. Paydar et al. (2010) applied simulated annealing for designing cellular manufacturing systems. Nouri and Hong (2013) developed a bacteria foraging optimization algorithm for cell formation in cellular manufacturing system considering cell load variations. Chandrasekar and Venkumar (2013) proposed a genetic algorithm method for integrating cell formation with machine layout and cell layout.

\section{The proposed study}

The proposed study of this paper considers the following objectives,

1. It groups equipment and part families.

2. The proposed method reduces depreciation cost as well as the cost of transportation from one period to another period,

3. It considers minimization of the cost of transportations of parts between and inside cells.

4. It reducing the number of exceptional parts.

5. It also reduces the number machine-movement from one cell to another one from one period to another.

\section{Assumptions}

1. Each part needs pre-specified operations and each operation has a known processing time.

2. The capacity of each machine is known in advance.

3. Parts are moved inside and between cells in batch and the cost of transportation is known.

4. There is a known maximum number of machines in each cell. 
5. Any machine can be moved from one cell to another between each period.

6. The cost of transportation between cells depends on the sequence of cells.

7. Each machine is capable of perform one type of operations.

8. The cost of transportation between cells is fixed.

9. No inventory exists between periods and there is no backorders.

10. All machines are operating with $100 \%$ efficiencies.

11. There is one line transportation operations.

12. The operations of each part on each machine is known in advance.

13. All machines are leased for operations.

14. The maintenance, depreciation and other machine related cost associated with each machine are fixed and known in advance.

15. The pleases assigned for all machines in every cells are known in advance.

\section{Symbols}

$\begin{array}{cll}i, i^{\prime} & \text { Index for machines } & i, i^{\prime}=1,2, \ldots, m \\ j & \text { Index for parts } & j=1,2, \ldots, n \\ p & \text { The position of each machine } & p=1,2, \ldots, m p \\ k, k^{\prime} & \text { Index for cells } & k, k^{\prime}=1,2, \ldots, C \\ h & \text { Index for planning time } & h=1,2, \ldots, H\end{array}$

\section{Parameters}

$B_{j} \quad$ Size of batch for movement of part $j$

$C_{\text {intra }}^{j}$ The cost of intera cell movement of each part $j$

$C_{\text {inter }}^{j} \quad$ The cost of movement of each part $j$ between cells

$C_{b a c k}^{j} \quad$ The cost of backward movement of each part $j$ inside the cell

$M_{i h} \quad$ The position of machine $i$ on period $h$

$R_{i j} \quad$ The number of operations for part $j$ on machine $i$

$D_{j h} \quad$ Demand for part $j$ in period $h$

NM Maximum number of machines in each cell

$f_{i i^{\prime} h}^{j} \quad$ Number of trips for transportation of part $j$ between cell $i$ and $i^{\prime}$ in period $h$

$f_{i i^{\prime} h}^{j}=\left\{\begin{array}{lll}{\left[D_{j h} / B_{j}\right]} & \text { if } & R_{i^{\prime} j}-R_{i j}=1 \\ 0 & \text { if } & R_{i^{\prime} j}-R_{i j} \neq 1\end{array}\right.$

$T_{i} \quad$ Capacity of machine $i$ in each period

$t_{i j} \quad$ Processing time of part $j$ by machine $i$

$S P \quad$ Set of $(i, j)$ for parts assigned to machines

$A_{i} \quad$ Fixed cost of machine $i$

$B_{i} \quad$ Cost of increase/decrease of machine $i$ which is considered to be fixed

$\alpha_{j} \quad$ The coefficient for each extra exception machine

\section{Variables}

$$
\begin{aligned}
X_{i k h} & = \begin{cases}1 & \text { if machine } i \text { is assigned to cell } k \text { in period } h \\
0 & \text { otherwise }\end{cases} \\
Y_{j k h} & = \begin{cases}1 & \text { if part } j \text { is assigned to cell } k \text { in period } h \\
0 & \text { otherwise }\end{cases} \\
Z_{i p h} & = \begin{cases}1 & \text { if machine } i \text { in period } h \text { is assigned to position } p \\
0 & \text { otherwise }\end{cases} \\
U_{i j k h} & = \begin{cases}1 & \text { if } X_{i k h}=1 \text { and } Y_{j k h}=0 \\
0 & \text { otherwise }\end{cases}
\end{aligned}
$$




$$
\begin{aligned}
& 410 \\
& \begin{array}{l}
V_{i j k h}= \begin{cases}1 & \text { if } Y_{j k h}=1 \text { and } X_{i k h}=0 \\
0 & \text { otherwise }\end{cases} \\
K A_{i h}
\end{array} \\
& K R_{i h} \quad \text { Number of machines type } i \text { which are deleted in each period } h \\
& N_{i h} \quad \text { Number of machines type } i \text { which are required for each period } h
\end{aligned}
$$

Therefore, the proposed model of this paper is stated as follows,

$$
\begin{aligned}
C_{i i^{\prime} h}^{j}=\left\{\begin{array}{llc}
\left(M_{i^{\prime} h}-M_{i h}\right) C_{i n t r a}^{j} & \text { if } & X_{i k h}, X_{i^{\prime} k h}>0, M_{i^{\prime} h}>M_{i h} \\
\left(M_{i h}-M_{i^{\prime} h}\right) C_{b a c k}^{j} & \text { if } & X_{i k h}, X_{i^{\prime} k h}>0, M_{i^{\prime} h}<M_{i h} \\
\left|k-k^{\prime}\right| C_{\text {inter }}^{j} & \text { if } & X_{i k h} X_{i^{\prime} k h}=0, X_{i k h} X_{i^{\prime} k^{\prime} h}>0
\end{array}\right. \\
\min \sum_{h=1}^{H} \sum_{j=1}^{n} \sum_{i=1}^{m} \sum_{i^{\prime}=1}^{m} f_{i i^{\prime} h}^{j} C_{i i^{\prime} h}^{j}+\sum_{h=2}^{H} \sum_{i=1}^{m} B_{i}\left(K A_{i h}+K R_{i h}\right)+\sum_{h=1}^{H} \sum_{i=1}^{m} A_{i} \cdot N_{i h}+\sum_{h=1}^{H} \sum_{k} \sum_{j} \sum_{(i, j) \in s p} \alpha_{j \cdot} \frac{\left(U_{i j k h}+V_{i j k h}\right)}{2}
\end{aligned}
$$

subject to

$\sum_{k=1}^{C} X_{i k h}=1, i=1,2, \ldots, m, \quad \forall h$

$\sum_{k=1}^{C} Y_{j k h}=1, j=1,2, \ldots, n, \quad \forall h$

$\sum_{i=1}^{m} X_{i k h} \leq N M, \quad k=1,2, \ldots, C, \quad \forall h$

$\sum_{i=1}^{m} Z_{i p h}=1, p=1,2, \ldots, m p, \quad \forall h$

$\sum_{p=1}^{m p} Z_{i p h}=1 \quad, i=1,2, \ldots, m, \quad \forall h$

$\left(\sum_{j=1}^{n} D_{j h} \cdot t_{i j}\right) / T_{i} \leq N_{i h} \quad \forall i, h$

$N_{i(h-1)}+K A_{i h}-K R_{i h}=N_{i h} \quad \forall i, k, h$

$K A_{\text {ih }} \times K R_{\text {ih }}=0 \quad \forall i, h$

$N_{\text {ih }}, K A_{\text {ih }}, K R_{\text {ih }} \geq 0$ and Integer

$X_{i k h}, Y_{j k h}, Z_{i p h}, W_{k k^{\prime} h}^{i}, U_{i j k h}, V_{i j k h}=0$ or 1

The proposed model given in Eqs. (1-12) presents a dynamic method to minimize different costs including the total cost of movements within and between cells and exceptional parts. The resulted problem is a nonlinear mixed integer programming problem. The objective function consists of four parts. The first part is associated with the cost of intera as well as inter cells transportations. The second part of the objective function is associated with the cost of adding/removing a machine inside a cell. The third part of the objective function is associated with the fixed cost maintenance, depreciation, etc. Finally, the last part tries to minimize the number of exceptional parts. 
Constraint (4) assures that each machine is assigned to only one cell. Eq. (5) specifies that each part is assigned only to one part group. Eq. (6) limits the number of machines assigned to each cell. Eq. (7) is to make sure that in each position only one machine is assigned. Eq. (8) is to make sure that in each period each machine is assigned to a particular position. Eq. (9) is to assure that in each period the load on each machine is not more than its capacity. Eq. (10) balances the number of machines, which are added/removed. According to Eq. (11), in each period, either a machine is added or removed. Finally, Eq. (12) determines the type of variables.

\section{Solution procedure}

The proposed study of this paper uses genetic algorithm to solve the results problem formulation.

\subsection{Genetic Algorithm}

Genetic algorithms are considered a method with an intelligent random search (Goldberg \& Holland, 1988) where in each iteration, it attempts to evolve the current generation into a new population. This procedure is repeated using selection, crossover, and mutation operators. Some of the chromosomes in the current generation are chosen by selection mechanism and used for the next generation. Also, some individuals are chosen from current population, as parents, to setup offspring by implementing the crossover operator. Finally, mutation operator is implemented to change some genes in some chromosomes. In other words, the mutation operator makes sure about the diversity of searching in solution space. The chromosome in this paper is defined in Fig. 1 as follows,

\begin{tabular}{|c|c|c|}
\hline$X_{1}, X_{2}, \ldots, X_{m}$ & $Y_{1}, Y_{2}, \ldots, Y_{m}$ & $Z_{1}, Z_{2}, \ldots, Z_{n}$ \\
\hline
\end{tabular}

Fig. 1. The arrangement of chromosome

According to Fig. 1, we understand that the longer the period of planning, the bigger the size of the chromosome. The length of the chromosome can be defined as follows,

(Number of different types of machines $\times 2+$ Number of parts $) \times($ Number of planning programs $)$

For instance, when there are 3 machines, 4 parts and 2 period of planning, the length of the chromosome will be 20 and we have

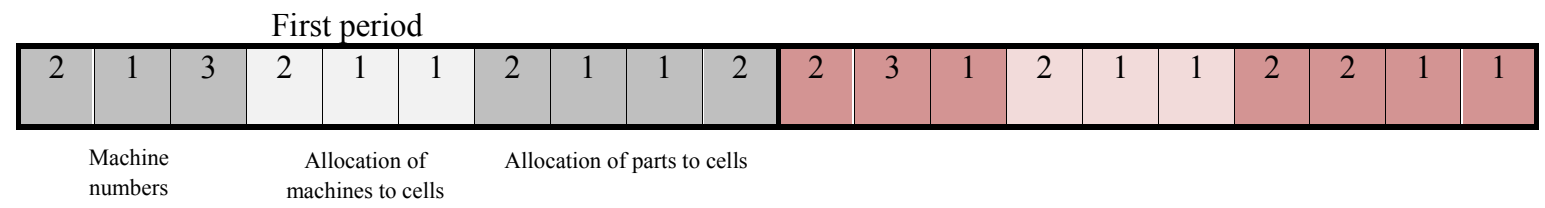

\begin{tabular}{|l|l|l|l|l|l|l|l|l|l|l|l|l|l|l|l|l|l|l|l|}
\hline 1 & 2 & 3 & 1 & 2 & 3 & 1 & 2 & 3 & 4 & 1 & 2 & 3 & 1 & 2 & 3 & 1 & 2 & 3 & 4 \\
\hline 2 & 1 & 3 & 2 & 1 & 1 & 2 & 1 & 1 & 2 & 2 & 3 & 1 & 2 & 1 & 1 & 2 & 2 & 1 & 1 \\
\hline
\end{tabular}

Fig. 2. The structure of Chromosome for 3 machines, 4 parts and 2 period of planning

The proposed study normally generates 50-100 chromosome during the initiation of the proposed study. Next, we perform crossover on the operations as shown in Fig. 3 as follows, 


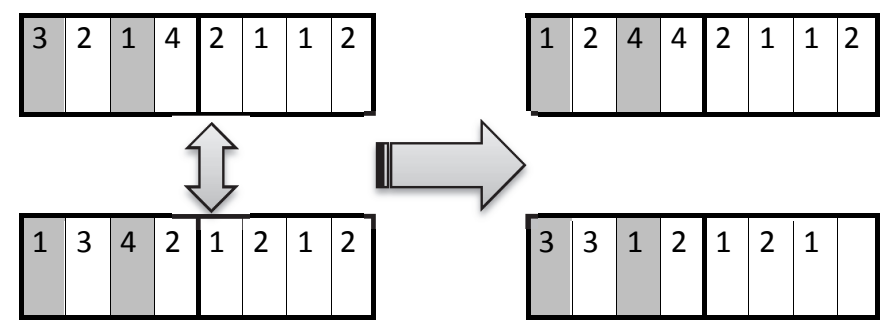

Fig. 3. Descrete crossover

In Fig. 3, there are some violations of constraints. For instance, in the first chromosome, machine 4 is assigned to two positions 3 and 4 while machine 3 is assigned to no position. The chromosome is adjusted as shown in Fig. 4 as follows,

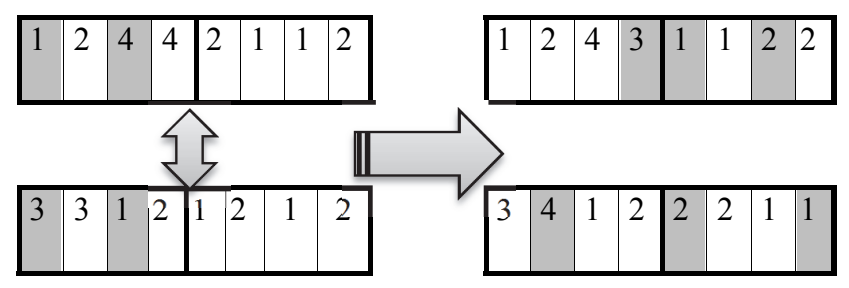

Fig. 4. The adjusted chromosome

The third part of the chromosome, which is assigned for part family can be represented in Fig. 5 as follows,
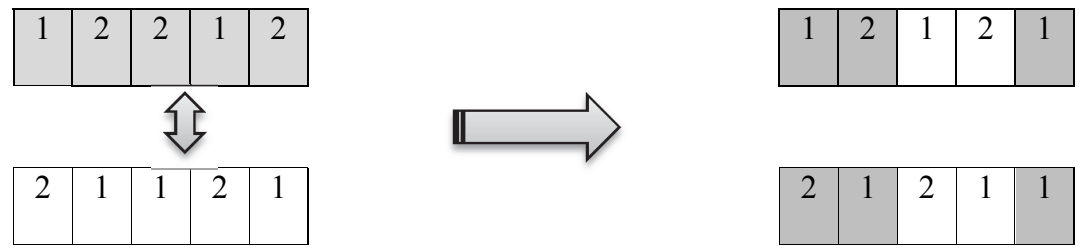

Fig. 5. Discrete crossover to create an infant in the cell formation

After applying the crossover operator, chromosomes go for mutation operation. We create random number for each cell of the chromosome and in case this number is less than $P_{m}$ the mutation is performed on that cell. In case the mutation operation is illegal according to the rules, we make some adjustments. For instance, consider the chromosome with 4 machines and 5 parts shown in Fig. 6 as follows,

\section{\begin{tabular}{|l|l|l|l|l|l|l|l|l|l|l|l|l|}
\hline 3 & 1 & 2 & 4 & 1 & 2 & 1 & 2 & 2 & 1 & 2 & 1 & 1 \\
\hline
\end{tabular}}

Fig. 6. A chromosome with 4 machines and 5 parts

To adjust the chromosome after implementing the mutation we have Fig. 6 as follows,

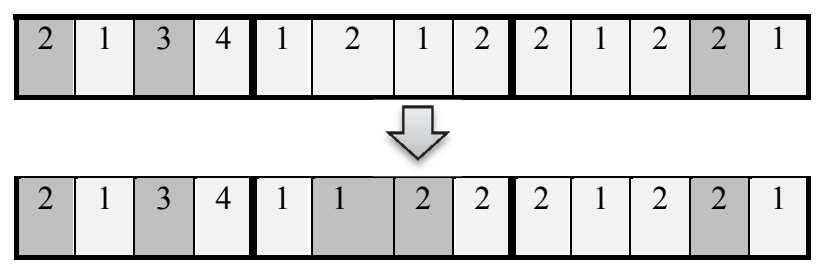

Fig. 7. Discrete crossover to create an infant 
The proposed study considers different conditions for terminating the algorithm such as reaching a predefined number of iterations, time, etc.

\section{The results}

In order to measure the performance of the proposed method, we have solved the proposed method for some instances using an optimization software and compared the results with the proposed GA. Table 1 demonstrates the input parameters used for the proposed study based on uniform distribution function.

\section{Table 1}

The input data used for the proposed study

\begin{tabular}{cc}
\hline Parameter & Value \\
\hline$B_{j}$ & $U(20,30)$ \\
$D_{j h}$ & $U(200,300)$ \\
$C_{\text {intra }}^{j}$ & 1 \\
$C_{\text {back }}^{j}$ & 3 \\
$C_{\text {inter }}^{j}$ & 7 \\
$C_{i}$ & $U(3000,4000)$ \\
$B_{i}$ & $U(4500,5500)$ \\
$A_{i}$ & $U(13000,17000)$ \\
$T_{i}$ & 1000 \\
$t_{i j}$ & $U(1,2)$ \\
$\alpha_{j}$ & $U(80,100)$ \\
\hline
\end{tabular}

We have used these numbers to solve the problem under three different conditions.

\subsection{Problem with 10 parts and 8 machines}

For this problem, the population of each generation is set to $100(\mu=100)$, the probability for crossover and mutation are $\left(p_{c}=0.9\right)$ and $\left(p_{m}=0.1\right)$, respectively. In addition, termination criterion is to reach 100 iterations. In addition, we assume there are three types of machines in each cell, there are three cells, the average number of operations is equal to 3 and machine part is as follows,

\begin{tabular}{c|cccccccccc|}
\multicolumn{1}{c}{} & $p_{1}$ & $p_{2}$ & $p_{3}$ & $p_{4}$ & $p_{5}$ & $p_{6}$ & $p_{7}$ & $p_{8}$ & $p_{9}$ & $p_{10}$ \\
\cline { 2 - 10 }$M_{1}$ & 0 & 1 & 0 & 3 & 0 & 0 & 2 & 0 & 0 & 1 \\
$M_{2}$ & 1 & 0 & 2 & 0 & 0 & 0 & 3 & 1 & 0 & 0 \\
$M_{3}$ & 0 & 0 & 0 & 1 & 2 & 3 & 0 & 0 & 0 & 0 \\
$M_{4}$ & 3 & 2 & 0 & 0 & 0 & 0 & 1 & 0 & 2 & 0 \\
$M_{5}$ & 0 & 0 & 3 & 0 & 1 & 0 & 0 & 2 & 0 & 3 \\
$M_{6}$ & 0 & 0 & 1 & 0 & 3 & 0 & 0 & 0 & 1 & 0 \\
$M_{7}$ & 0 & 3 & 0 & 2 & 0 & 1 & 0 & 0 & 0 & 2 \\
$M_{8}$ & 2 & 0 & 0 & 0 & 0 & 2 & 0 & 3 & 0 & 0 \\
\cline { 2 - 9 } & & & & & & & &
\end{tabular}

Table 2 presents details of the final solutions for two methods.

Table 2

The results of comparison of GA versus optimal solution using Lingo software

\begin{tabular}{cccccccc}
\hline & Obj. Func. & Rent & Add/remove cost & $\begin{array}{c}\text { Displacement } \\
\text { of machines }\end{array}$ & $\begin{array}{c}\text { Displacement } \\
\text { of parts }\end{array}$ & $\begin{array}{c}\text { Exceptional } \\
\text { parts }\end{array}$ & Time \\
\hline Lingo & 125959 & 125280 & 0 & 0 & 372 & 307 & 148.4 \\
GA & 125959 & 125280 & 0 & 0 & 372 & 307 & 32.47 \\
\hline
\end{tabular}

According to the results of Table 2, both methods reach the optimal solution and with the same numbers. 


\subsection{Problem with 14 parts and 9 machines}

For this problem, the population of each generation is set to $100(\mu=100)$, the probability for crossover and mutation are $\left(p_{c}=0.9\right)$ and $\left(p_{m}=0.1\right)$, respectively. Moreover, termination criterion is to reach 100 iterations. In addition, we assume there are three types of machines in each cell, there are three cells, the average number of operations is equal to 4 and machine part is as follows,

\begin{tabular}{c|cccccccccccccc|}
\multicolumn{1}{c}{} & $p_{1}$ & $p_{2}$ & $p_{3}$ & $p_{4}$ & $p_{5}$ & $p_{6}$ & $p_{7}$ & $p_{8}$ & $p_{9}$ & $p_{10}$ & $p_{11}$ & $p_{12}$ & $p_{13}$ & $p_{14}$ \\
$M_{1}$ & 0 & 1 & 0 & 3 & 0 & 0 & 2 & 0 & 0 & 1 & 0 & 0 & 2 & 0 \\
$M_{2}$ & 1 & 0 & 2 & 0 & 0 & 0 & 3 & 1 & 0 & 0 & 0 & 2 & 0 & 0 \\
$M_{3}$ & 0 & 0 & 0 & 1 & 2 & 4 & 0 & 0 & 0 & 0 & 3 & 0 & 3 & 1 \\
$M_{4}$ & 3 & 2 & 0 & 0 & 0 & 0 & 1 & 0 & 2 & 0 & 0 & 1 & 0 & 0 \\
$M_{5}$ & 0 & 0 & 3 & 0 & 1 & 0 & 0 & 2 & 0 & 3 & 0 & 0 & 0 & 3 \\
$M_{6}$ & 0 & 0 & 1 & 0 & 3 & 0 & 0 & 0 & 1 & 0 & 2 & 0 & 0 & 4 \\
$M_{7}$ & 0 & 3 & 0 & 2 & 0 & 1 & 0 & 4 & 0 & 4 & 0 & 3 & 0 & 0 \\
$M_{8}$ & 2 & 0 & 0 & 0 & 4 & 2 & 0 & 3 & 0 & 0 & 1 & 0 & 0 & 2 \\
$M_{9}$ & 0 & 0 & 4 & 0 & 0 & 3 & 0 & 0 & 3 & 2 & 0 & 0 & 1 & 0 \\
\cline { 2 - 12 }
\end{tabular}

Table 3 presents details of the final solutions for two methods.

Table 3

The results of comparison of GA versus optimal solution using Lingo software

\begin{tabular}{cccccccc}
\hline & Obj. Func. & Rent & Add/remove cost & $\begin{array}{c}\text { Displacement } \\
\text { of machines }\end{array}$ & $\begin{array}{c}\text { Displacement } \\
\text { of parts }\end{array}$ & $\begin{array}{c}\text { Exceptional } \\
\text { parts }\end{array}$ & Time \\
\hline Lingo & 142242.5 & 140652 & 0 & 0 & 903 & 687.5 & 902.85 \\
GA & 142242.5 & 140652 & 0 & 0 & 903 & 687.5 & 50.51 \\
\hline
\end{tabular}

One more time, both methods have reached the same results and they are different only in terms of CPU time. For this problem, the first cell contains machine number 4, 6 and 7 and parts, 1, 7 and 9. The second cell includes machines 1,2 and 8 and parts $\{2,5,4,6,8,10,11,13,14\}$. Finally, cell number 3 includes $\{3,5,9\}$ and parts $\{3,12\}$.

\subsection{Problem with 14 parts and 7 machines}

For this problem, the population of each generation is set to $100(\mu=100)$, the probability for crossover and mutation are $\left(p_{c}=0.9\right)$ and $\left(p_{m}=0.1\right)$, respectively. Moreover, termination criterion is to reach 100 iterations. In addition, we assume there are three types of machines in each cell, there are three cells, the average number of operations is equal to 3 , there are two periods and machine part is as follows,

\begin{tabular}{l|cccccccccccccc|}
\multicolumn{1}{c}{} & $p_{1}$ & $p_{2}$ & $p_{3}$ & $p_{4}$ & $p_{5}$ & $p_{6}$ & $p_{7}$ & $p_{8}$ & $p_{9}$ & $p_{10}$ & $p_{11}$ & $p_{12}$ & $p_{13}$ & $p_{14}$ \\
\cline { 3 - 13 } & 0 & 2 & 0 & 0 & 1 & 0 & 0 & 1 & 1 & 0 & 0 & 0 & 0 & 1 \\
$M_{2}$ & 3 & 0 & 0 & 2 & 3 & 3 & 1 & 0 & 0 & 0 & 0 & 0 & 0 & 0 \\
$M_{3}$ & 0 & 0 & 0 & 0 & 0 & 0 & 0 & 0 & 0 & 2 & 2 & 2 & 1 & 0 \\
$M_{4}$ & 0 & 0 & 1 & 0 & 0 & 0 & 2 & 0 & 2 & 1 & 1 & 1 & 0 & 0 \\
$M_{5}$ & 0 & 1 & 0 & 0 & 0 & 0 & 0 & 2 & 0 & 0 & 0 & 0 & 0 & 2 \\
$M_{6}$ & 2 & 0 & 0 & 0 & 0 & 2 & 0 & 3 & 0 & 0 & 0 & 0 & 0 & 0 \\
$M_{7}$ & 1 & 0 & 0 & 1 & 2 & 1 & 0 & 0 & 3 & 0 & 0 & 0 & 0 & 2 \\
\cline { 2 - 12 }
\end{tabular}

Table 4 shows details of the final solutions for two methods.

Table 4

The results of comparison of GA versus optimal solution using Lingo software

\begin{tabular}{cccccccc}
\hline & Obj. Func. & Rent & Add/remove cost & $\begin{array}{c}\text { Displacement } \\
\text { of machines }\end{array}$ & $\begin{array}{c}\text { Displacement } \\
\text { of parts }\end{array}$ & $\begin{array}{c}\text { Exceptional } \\
\text { parts }\end{array}$ & Time \\
\hline Lingo & 147117.2 & 112994 & 20684 & 10750 & 1564.2 & 1125 & 2407.8 \\
GA & 147117.2 & 112994 & 20684 & 10750 & 1564.2 & 1125 & 131.02 \\
\hline
\end{tabular}


One more time, both methods reached the optimal solutions under different CPU time. The following demonstrate the position of machines to different locations.

\begin{tabular}{l|ccccccc|}
\multicolumn{1}{c}{} & Position 1 & Position 2 & Position 3 & Position 4 & Position 5 & Position 6 & Position 7 \\
\cline { 2 - 8 } Period 1 & 3 & 4 & 7 & 2 & 1 & 5 & 6 \\
Period 2 & 3 & 4 & 1 & 7 & 5 & 6 & 2 \\
\hline
\end{tabular}

In addition, the positions of machines to different cells.

\begin{tabular}{l|ccccccc|}
\multicolumn{1}{l}{} & $M_{1}$ & $M_{2}$ & $M_{3}$ & $M_{4}$ & $M_{5}$ & $M_{6}$ & $M_{7}$ \\
\cline { 2 - 8 } Period 1 & 2 & 2 & 1 & 1 & 3 & 3 & 2 \\
Period 2 & 2 & 3 & 1 & 1 & 3 & 3 & 2 \\
\cline { 2 - 9 } & & & & &
\end{tabular}

Finally, the allocation of parts to cells are summarized as follows,

\begin{tabular}{l|cccccccccccccc|}
\multicolumn{1}{l}{} & $p_{1}$ & $p_{2}$ & $p_{3}$ & $p_{4}$ & $p_{5}$ & $p_{6}$ & $p_{7}$ & $p_{8}$ & $p_{9}$ & $p_{10}$ & $p_{11}$ & $p_{12}$ & $p_{13}$ & $p_{14}$ \\
Period 1 & 3 & 1 & 3 & 1 & 2 & 1 & 1 & 3 & 3 & 3 & 3 & 3 & 2 & 1 \\
Period 2 & 3 & 1 & 3 & 3 & 2 & 3 & 2 & 2 & 1 & 2 & 3 & 1 & 3 & 2 \\
\hline
\end{tabular}

\section{Conclusion}

In this paper, we have presented a dynamic method to minimize different costs including the total cost of movements within and between cells and exceptional parts. In this study, the Hierarchical Genetic Algorithm (HGA) has been used for solving the resulted model and the results are compared with genetic algorithm. The results have indicated that the proposed model was capable of detecting optimal solutions in reasonable amount of time for small and middle scale problems. This survey can be extended to a new research areas by considering uncertainty on different parameters such as processing times, cost of transportation, etc. and we leave it as a future research for interested researchers.

\section{Acknowledgement}

The authors would like to thank the anonymous referees for constructive comments on earlier version of this paper.

\section{References}

Ahi, A., Aryanezhad, M. B., Ashtiani, B., \& Makui, A. (2009). A novel approach to determine cell formation, intracellular machine layout and cell layout in the CMS problem based on TOPSIS method. Computers \& Operations Research, 36(5), 1478-1496.

Alfa, A. S., Chen, M., \& Heragu, S. S. (1992). Integrating the grouping and layout problems in cellular manufacturing systems. Computers \& Industrial Engineering, 23(1), 55-58.

Balasubramanian, K. N., \& Panneerselvam, R. (1993). Covering technique-based algorithm for machine grouping to form manufacturing cells. The International Journal of Production Research, 31(6), 1479-1504.

Chan, F. T. S., Lau, K. W., Chan, L. Y., \& Lo, V. H. Y. (2008). Cell formation problem with consideration of both intracellular and intercellular movements.International Journal of Production Research, 46(10), 2589-2620.

Chang, C. C., Wu, T. H., \& Chung, S. H. (2009, September). A novel approach for cell formation and cell layout design in cellular manufacturing system. In Management and Service Science, 2009. MASS'09. International Conference on (pp. 1-4). IEEE.

Chandrasekharan, M. P., \& Rajagopalan, R. (1993). A multidimensional scaling algorithm for group layout in cellular manufacturing. International Journal of Production Economics, 32(1), 65-76.

Chandrasekar, K., \& Venkumar, P. (2013). Genetic algorithm approach for integrating cell formation with machine layout and cell layout. International Journal of Operational Research, 16(2), 155171. 
Co, H. C., \& Araar, A. (1988). Configuring cellular manufacturing systems.The International Journal Of Production Research, 26(9), 1511-1522.

Dixit, A. R., \& Mishra, P. K. (2009). Ex-CLASS: Extended Cell formation and LAyout Selection considering production parameters with Sequence data.International Journal of Product Development, 10(1-3), 180-200.

Goldberg, D. E., \& Holland, J. H. (1988). Genetic algorithms and machine learning. Machine learning, 3(2), 95-99.

Houshyar, A., \& McGINNIS, L. F. (1990). A heuristic for assigning facilities to locations to minimize WIP travel distance in a linear facility. The International Journal of Production Research, 28(8), 1485-1498.

Hwang, C.L., \& Yoon, K. (1981). Multiple Attribute Decision Making: Methods and Applications. New York: Springer-Verlag.

Logendran, R. (1991). Impact of sequence of operations and layout of cells in cellular manufacturing. The International Journal of Production Research, 29(2), 375-390.

Mahdavi, I., \& Mahadevan, B. (2008). CLASS: An algorithm for cellular manufacturing system and layout design using sequence data. Robotics and Computer-Integrated Manufacturing, 24(3), 488497.

Mahdavi, I., Paydar, M. M., Solimanpur, M., \& Saidi-Mehrabad, M. (2010). A mathematical model for integrating cell formation problem with machine layout. International Journal of Industrial Engineering, 21(2), 61-70.

Ming, L. C., \& Ponnambalam, S. G. (2008, October). A hybrid GA/PSO for the concurrent design of cellular manufacturing system. In Systems, Man and Cybernetics, 2008. SMC 2008. IEEE International Conference on (pp. 1855-1860). IEEE.

Nouri, H., \& Hong, T. S. (2013). Development of bacteria foraging optimization algorithm for cell formation in cellular manufacturing system considering cell load variations. Journal of Manufacturing Systems, 32(1), 20-31.

Paydar, M. M., Mahdavi, I., Solimanpur, M., \& Tajdin, A. (2008, December). Solving a new mathematical model for cellular manufacturing system: fuzzy goal programming. In Industrial Engineering and Engineering Management, 2008. IEEM 2008. IEEE International Conference on (pp. 1224-1228). IEEE.

Paydar, M. M., Mahdavi, I., Sharafuddin, I., \& Solimanpur, M. (2010). Applying simulated annealing for designing cellular manufacturing systems using MDmTSP. Computers \& Industrial Engineering, 59(4), 929-936.

Tavakkoli-Moghaddam, R., Javadian, N., Javadi, B., \& Safaei, N. (2007). Design of a facility layout problem in cellular manufacturing systems with stochastic demands. Applied Mathematics and Computation, 184(2), 721-728.

Vakharia, A. J., \& Wemmerlov, U. (1990). Designing a cellular manufacturing system: a materials flow approach based on operation sequences. IIE transactions, 22(1), 84-97. 